\title{
CARDIOPULMONARY BYPASS-INDUCED INCREASE OF SERUM INTERLEUKIN-10 LEVELS IN CHILDREN
}

\author{
Attila Tárnok, PhD, Jörg Hambsch, MD, and Peter Schneider, MD, Leipzig, Germany
}

During pediatric cardiac operations with cardiopulmonary bypass (CPB), the serum levels of various inflammatory cytokines change dramatically. ${ }^{1}$ Recent studies in children demonstrate that interleukin-10 (IL-10), a cytokine that acts in an immunosuppressive manner, is liberated during ${ }^{2}$ or after $^{3}$ pediatric cardiac operations. The information provided by these authors, however, are conflicting with respect to the amplitude and the kinetics of secreted IL-10. ${ }^{2,3}$ Seghaye and colleagues ${ }^{2}$ reported two peaks of IL-10 release, one during and a second after CPB, with maximums at the end of CPB and 1 day after the operation, respectively. Data from Sugita and associates $^{3}$ indicate earlier IL-10 release, with maximums during reperfusion and a few hours after the operation. Their data are similar to data reported for adults ${ }^{4}$ with respect to the kinetics of IL-10 release. In contrast, Sugita and associates $^{3}$ reported initial and peak IL-10 values that were more than 10 times as high as in adults ${ }^{4}$ and in infants until 10 months after birth. ${ }^{2}$ We analyzed the kinetics of IL-10, interleukin-6 (IL-6) and tumor necrosis factor- $\alpha$ (TNF- $\alpha)$ release in children undergoing cardiac operations to clarify the release pattern of IL-10 in children.

From Pediatric Cardiology, Cardiac Center Leipzig, University Hospital, Leipzig, Germany.

Received for publication April 29, 1997; accepted for publication Sept. 9, 1997.

Address for reprints: Attila Tárnok, PhD, Pediatric Cardiology, Cardiac Center Leipzig, University Hospital, Russenstr. 19, D-04289 Leipzig, Germany.

J Thorac Cardiovasc Surg 1998;115:475-7

Copyright (C) 1998 by Mosby, Inc.

0022-5223/98 $\$ 5.00+0 \quad \mathbf{1 2 / 5 4 / 8 5 9 9 2}$
Patients and methods. After informed consent was obtained, 24 children with atrial septal defects (atrial septal defect I, $n=1$; atrial septal defect II, $n=13$ ) or ventricular septal defects $(n=10)$ undergoing cardiac operations were analyzed. The surgical procedures were ventricular septal defect closure and atrial septal defect repair, respectively. General anesthesia and myoplegia were performed with midazolam, fentanyl, and pancuronium. CPB was performed with a roller pump (Stöckert Instrumente $\mathrm{GmbH}$, Munich, Germany) and hollow-fiber oxygenator (DIDECO, Mirandola, Italy). The priming solution consisted of a crystalloid solution, mannitol (3 $\mathrm{ml} / \mathrm{kg}$ body weight), and Iono-lactat (Fresenius, Bad Homburg, Germany). In a few cases, priming was completed with compatible erythrocyte concentrate. During $\mathrm{CPB}$, the hematocrit level was kept at $22 \%$ to $30 \%$ and the flow rate was maintained at 2.7 to $3.5 \mathrm{~L} / \mathrm{m}^{2} / \mathrm{min}$. Hypothermia was induced by cooling priming solution and circulating blood with the heat exchanger. During the cooling period, all patients received sodium nitroprusside ( 0.3 to $2.0 \mu \mathrm{g} / \mathrm{kg} / \mathrm{min}$ ) for vasodilatation. Bretschneider's cardioplegic solution was used for myocardial perfusion. Our perioperative antibiotic regimen consisted of cefazolin (50 mg/kg body weight) in three separate doses. During rewarming, heated and humidified inspired gases were used and sodium nitroprusside was administered intravenously. At the end of CPB, all but one patient underwent hemofiltration, normal flow was reestablished, and the patients were rewarmed. The lungs were reventilated and heparin was neutralized with protamine sulfate. In all but two cases, a catecholamine (dobutamine or dopamine at 2 to $6 \mu \mathrm{g} / \mathrm{kg} / \mathrm{min}$ ) was infused before the patients were weaned from bypass. No corticosteroids were applied before, during, or after the operation.

Blood samples were collected 1 day before the operation (-1d); after the onset of anesthesia (anesthesia); 10 

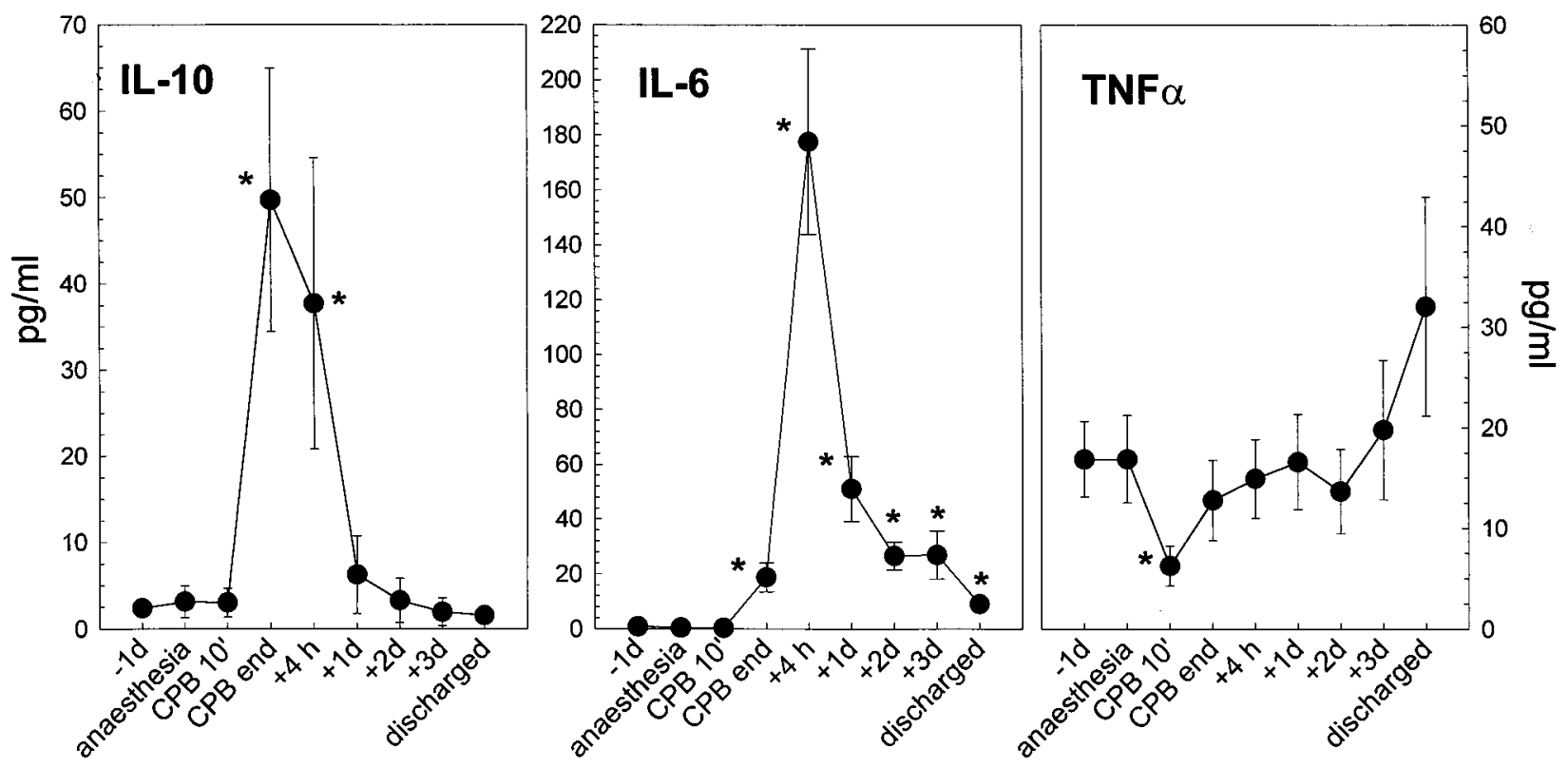

Fig. 1. Alterations of serum concentrations of IL-10, IL-6, and TNF- $\alpha$ in children undergoing heart operations with CPB. Data display mean values of 24 children. Error bars indicate standard error of the mean. Asterisks indicate values significantly different from basal values $(p<0.05)$.

Table I. Patient and surgical data

\begin{tabular}{lcc}
\hline \multicolumn{1}{c}{ Clinical data } & $\begin{array}{c}\text { Mean } \pm \text { standard } \\
\text { deviation }\end{array}$ & range \\
\hline Age $(\mathrm{yr})$ & $7.42 \pm 1.98$ & $5.08-11.08$ \\
Weight $(\mathrm{kg})$ & $24.57 \pm 7.98$ & $12.5-39.5$ \\
Surgical duration (min) & $173.6 \pm 57.7$ & $60-280$ \\
CPB duration (min) & $57.6 \pm 33.9$ & $23-109$ \\
AXT duration (min) & $30.3 \pm 25.3$ & $12-76$ \\
Minimal rectal & $31.9 \pm 3.6$ & $23.0-36.2$ \\
$\quad$ temperature $\left({ }^{\circ} \mathrm{C}\right)$ & $460 \pm 386$ & $150-1,200$ \\
Hemofiltration volume & & \\
$\quad(\mathrm{ml})$ & (patient without filtration) & \\
\hline
\end{tabular}

$A X T$, Aortic crossclamping.

minutes after onset of $\mathrm{CPB}$; before the end of the $\mathrm{CPB}$ during rewarming ( $\mathrm{CPB}$ end); 4 to 6 hours after the operation and protamine administration $(+4 \mathrm{~h}) ; 1,2$, and 3 days after the operation $(+1 \mathrm{~d},+2 \mathrm{~d}$, and $+3 \mathrm{~d})$; and shortly before discharge (discharged). Blood was collected in untreated tubes (IL-10 and IL-6) or tubes treated with ethylenediaminetetraacetic acid (EDTA; TNF- $\alpha$ ), and serum or EDTA-treated plasma samples were stored within 30 to 40 minutes after sampling at $-80^{\circ} \mathrm{C}$ until analysis. Cytokine concentrations were determined by enzyme-linked immunoabsorbent assay. The detection ranges were 16 to $2000 \mathrm{pg} / \mathrm{ml}$ for IL-10 assay (sensitivity $1.5 \mathrm{pg} / \mathrm{ml}$; Boehringer Ingelheim, Ingelheim, Germany), 3.13 to $300 \mathrm{pg} / \mathrm{ml}$ for IL-6 (sensitivity $0.7 \mathrm{pg} / \mathrm{ml}$, Quantikine; R\&D Systems, Minneapolis, Minn.), and 15.6 to $1000 \mathrm{pg} / \mathrm{ml}$ for TNF- $\alpha$ (sensitivity $5 \mathrm{pg} / \mathrm{ml}$; Immunotech,
Hamburg, Germany). Data obtained during CPB were not corrected for hemodilution. Statistical analysis was done with paired two-tailed Student's $t$ tests.

Results. Patients and surgical data are shown in Table I. The surgical and clinical outcomes were good for all children. Twelve of the children had minor postoperative complications such as pericardial effusion, edema, and liver swelling. Fig. 1 shows the kinetics of the analyzed serum parameters. Mean IL-10 level before the operation was $2.3 \pm 3.6 \mathrm{pg} / \mathrm{ml}$ (mean \pm standard deviation; range 0.0 to $14.6 \mathrm{pg} / \mathrm{ml})$. IL-10 concentration rose, with highest values during reperfusion $(50.0 \pm 71.6 \mathrm{pg} / \mathrm{ml}, p=0.003)$, remained elevated as long as 4 hours after the operation $(p=0.04)$, and was at baseline later on. The basal TNF- $\alpha$ level was $16.9 \pm 17.6 \mathrm{pg} / \mathrm{ml}$ (range 0.0 to $61.9 \mathrm{pg} / \mathrm{ml}$ ); it decreased significantly during CPB $(p=0.004$ at 10 minutes of $\mathrm{CPB}$ ), returned to basal levels 1 day after the operation, and was not significantly increased after the operation. Il-6 levels were initially low $(1.0 \pm 1.8 \mathrm{pg} / \mathrm{ml}$; range 0.0 to $7.2 \mathrm{pg} / \mathrm{ml}$ ). IL-6 increased during reperfusion $(p=0.003)$, with a maximum 4 hours after the operation $(p=0.00005)$, and remained elevated after the operation $(p=0.02)$. There were no clear differences in the release patterns of IL-10, IL-6, and TNF- $\alpha$ between children with and without catecholamine administration. Linear regression analysis demonstrated no correlation of peak IL-10 levels with minimal rectal temperature during bypass and preoperative, intraoperative, or postoperative TNF- $\alpha$ levels $\left(r^{2}<0.02\right)$. In contrast, peak IL-10 levels at reperfusion were slightly positively correlated with IL-6 levels determined at the same time $\left(r^{2}=0.35\right)$.

Discussion. The kinetics of IL-10 secretion we saw during pediatric cardiac operations are in apparent con- 
flict with data recently published by Seghaye and colleagues. ${ }^{2}$ They are similar to data presented by Sugita and associates $^{3}$ for children and by Tabardel and coworkers ${ }^{4}$ for adults. Whereas Sugita and associates ${ }^{3}$ and we found an immediate increase in IL-10 levels after the operation and normal levels 1 day later, Seghaye and colleagues ${ }^{2}$ reported a second, more pronounced peak 1 day after the operation. The first peak in the study of Seghaye and colleagues $^{2}$ is similar in amplitude to our findings but a tenth that reported by Sugita and coworkers. ${ }^{3}$ Our preoperative serum levels of IL-10 and TNF- $\alpha$ are in agreement with data reported for infants ${ }^{2}$ and adults. ${ }^{4}$

In contrast to the study of Seghaye and colleagues, ${ }^{2}$ there were no increased TNF- $\alpha$ levels during CPB. This difference between the studies potentially arises from two different mechanisms underlying the IL-10 secretion. As previously shown, ${ }^{5}$ there are two major producers of IL-10 in human beings, monocytes and T lymphocytes. Activated monocytes secrete IL-10 after stimulation with TNF- $\alpha$, whereas IL-10 secretion from activated T cells is triggered by interleukin-12, IL-6, or both. In our study, IL-10 levels did not correlate with TNF- $\alpha$ levels before or during the operation. In contrast, Il-6 levels correlated slightly with IL-10 levels during reperfusion. From these data, we conclude that $\mathrm{T}$ cells were probably the major source of IL-10 in our patients. This hypothesis is supported by our recent finding that monocyte activity (e.g., class II major histocompatibility complex expression) is regulated downward immediately after the start of the surgical procedure. ${ }^{1}$ Similar results were reported by Habermehl (Habermehl P, University of Mainz, Germany; unpublished observations). During CPB, the phenotype of T lymphocytes changes into "naive" (CD45RA expressing) T lymphocytes. "Naive" $\mathrm{T}$ lymphocytes tend to develop into helper-2 T lymphocytes and secrete IL-10, among other factors, on appropriate stimulation. ${ }^{6}$ A similar response could have occurred in the patient group analyzed by us, that analyzed by Sugita and associates, ${ }^{3}$ and in adults. ${ }^{4}$ In the study of Seghaye and colleagues, ${ }^{2}$ on the other hand, mainly activated monocytes could have contributed to the postoperative IL-10 secretion.

Comparison of anesthesia, medication, and surgical and postoperative protocols did not show major discrepancies between the study of Seghaye and colleagues ${ }^{2}$ and our study that could explain the measured differences. Although the mean durations of the surgical procedures, $\mathrm{CPB}$, and aortic crossclamping were lower and the minimal temperature was higher than in the study of Seghaye and colleagues, ${ }^{2}$ these values had a broadly overlapping distribution in the two studies. In our study, even in patients with the longest procedures, $\mathrm{CPB}$, and cross- clamp time, no second IL-10 peak was detectable. The patient data suggest, however, that the ages of the children may play a crucial role in the release kinetics of IL-10 and the type of cells involved. In the study of Seghaye and colleagues, ${ }^{2}$ infants 2 to 10 months old were analyzed. In our study and that of Sugita and associates, ${ }^{3}$ the children were older. This difference could indicate that the mechanism of IL-10 induction by CPB in patients with congenital heart disease is age dependent and develops from a mostly monocyte-dependent to a T cell-specific response. This could explain why IL-10 release during cardiac operations in adults ${ }^{4}$ follows mostly the kinetics we found. In addition, age-related differences in surgical procedure, other type of extracorporeal circuit, non-whole-blood priming, and hemofiltration may have altered the immune response. In an extended study, we have started to analyze the release pattern of cytokines during cardiac operations in infants and perform in vitro studies to scrutinize the source of IL-10. We believe that a clarification of the age dependency of the immune response could finally lead to more age-specific therapy.

\section{REFERENCES}

1. Tárnok A, Hambsch J, Borte M, Schneider P. Cardiac and vascular surgery induced immunological changes: influence of the cardio-pulmonary bypass. In: Faist E, editor. Proceedings of the 4th International Congress on the Immune Consequences of Trauma, Shock and Sepsis. Bologna, Italy: Monduzzi Editore; 1997. p. 129-33.

2. Seghaye M-C, Duchateau J, Bruniaux J, Demontoux S, Bosson $\mathrm{C}$, Serraf A, et al. Interleukin-10 release related to cardiopulmonary bypass in infants undergoing cardiac operations. J Thorac Cardiovasc Surg 1996;111:545-53.

3. Sugita T, Watarida S, Katsuyama K, Nakajima Y, Yamamoto $\mathrm{R}$, Mori A. Interleukin-10 release related to cardiopulmonary bypass in infants undergoing cardiac operations [letter]. J Thorac Cardiovasc Surg 1996;112:1127.

4. Tabardel Y, Duchateau J, Schmartz D, Marecaux G, Shahla $\mathrm{M}$, Barvais L, et al. Corticosteroids increase blood interleukin-10 levels during cardiopulmonary bypass in men. Surgery 1996;119:76-80.

5. Daftarian PM, Kumar A, Kryworuchko M, Diaz-Mitoma F. IL-10 production is enhanced in human T cells by IL-12 and IL- 6 and in monocytes by tumor necrosis factor $-\alpha$. J Immunol 1996;157:12-20.

6. Brinkmann V, Kristofic C. Regulation by corticosteroids of Th1 and Th2 cytokine production in human CD4+ effector T cells generated from CD45RO-and CD45RO+ subsets. J Immunol 1995;155:3322-8. 